\title{
A Comparison of the Use of Painted Faces in the Peking Opera with the Use of Masks in Western Theater
}

\author{
Jao-Hsun Tseng \\ Dance Department \\ National Taiwan University of Arts \\ New Taipei City, Taiwan \\ t0190@ntua.edu.tw
}

\author{
Po-Hsien Lin \\ Crafts and Design Department \\ National Taiwan University of Arts \\ New Taipei City, Taiwan \\ t0131@ ntua.edu.tw
}

\begin{abstract}
One of the most typical features of the Peking opera is its use of vivid makeup, especially in its variety of painted faces. The idea of the painted face was derived from the mask. Like masks in the western theater, painted faces generate the effect of facial transformation. Painted faces and masks share some common functions, reflecting the essence of the theatrical art. This study examines the origin and development of painted faces in Peking opera and of masks in the western theater. Through extensive comparisons and analyses, this study attempts to explore similarities and differences of these theatrical disguises in terms of ontology, aetiology, performance style, artistic expression, and cultural significance.
\end{abstract}

Keywords-Peking opera; painted face; mask; theatrical disguise

\section{INTRODUCTION}

Role-playing is one of the essential characteristics of theatrical art. Oscar G. Brockett points out that theater has been said to die each night; it only exists during the moments when actors are performing for the audience on the stage [1]. In front of the audience, the actor has to disguise his/her real identity and pretend to be the assigned character. Makeup and costume are two means of fulfilling this function. Another is the mask.

Ontologically, masks and makeup are two different forms of disguise. However, the exaggerated makeup of the painted face has become a well-known characteristic of Peking opera. Like masks in the western theater, painted faces generate the effect of facial transformation. Indeed, painted faces and masks share some common functions, reflecting the essence of the theatrical art. This paper will first discuss the origin and development of painted faces in Peking opera and of masks in the western theater. Subsequently, the paper will compare similarities and differences of these theatrical disguises in terms of ontology, aetiology, performance style, artistic expression, and cultural significance.

\section{THE USE OF MASKS IN WESTERN THEATER}

The mask is one of the oldest props used in theatrical art. Brockett points out that the most widely accepted theory of its origins, which was championed by anthropologists in the late nineteenth century, envisions theater as emerging out of myths and rituals in which performers wear costumes and masks to represent mythical characters or supernatural forces [2]. Western theater can be traced back to ancient Greece and the first definite record of theatrical activity there is found in 534 B.C. Thespis, who won the first contest for the best tragedy in the city of Dionysia, is the first known dramatist. According to Brockett, Thespis's drama involved only one actor and a chorus. Thus, the single actor had to use masks to change his identity [1].

Drama was performed in Greece for many centuries, and the constant use of masks had much to do with Greek performing style. In conventional Greek tragedy, the theater usually held before at least fourteen thousand spectators. All actors were male. Only three main actors could speak at a time, and they each played multiple parts (five main actors were occasionally required in comedy). Masks, which included the hair and headdress, covered the entire head. Their design and application, according to Brockett, had four basic purposes: first, to enable rapid change of roles; second, to male actors to represent female characters; third, to enlarge the range of character types which could be played by a limited number of actors; and fourth, in large theaters, to enhance the depiction of vivid features and to highlight the salient qualities of each character [3]. Brockett suggests another important function of masks: to simplify the problem of casting roles of identical appearance, such as those of the twins in Plautus's The Menaechmi [2]. It has been asserted that masks could have been used as megaphones but this has not been supported by evidence [1].

Mimic drama is another important theatrical form in which masks were widely used. Nicoll points out that masks have been associated with the ancient Dorian mime, particularly in Megara, which was developed prior to the appearance of Athenian drama. Masks were also used in some of the Phlyakes and Atellan farces which were developed in southern and central Italy [13].

The Roman theater inherited the use of masks. Brockett claims that all the cultures which influenced Rome, including those of Etruria, Greece, and southern Italy, had used masks in their entertainment. It is usually believed that Roman masks for comedy and tragedy resembled those used in the Greek theater. 
Some historians believe that the actors of the Roman mime did not usually wear masks because facial expressions were important in their performances. Basing his claim upon the writings of Marcus Fabius Quintilian, a rhetorician writing in the first century A.D., Brockett wrirtes that as mime became increasingly popular throughout the empire, the use of masks in the Roman theater became less common [2]. Although writing prior to Brockett, Nicoll responded to similar claims by maintaining that "such an assertion seems to demand qualification" [13]. Pointing out that following its introduction by Pomponius, a dramatist who wrote between 100 and 75 B.C., the Atellan style of mimic drama became a popular Roman mime form. Masks were used in the Atellan farce to create the stock characters. Figure 1 shows Dossennus, a stock type who was related to Pulcinella, a famous stock character in later Italian commedia dell' arte [13].

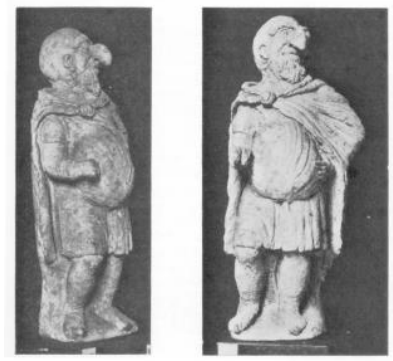

FIGURE 1.

DOSSENNUS: A STOCK CHARACTER IN ATELLAN FARCE.

Allardyce Nicoll, Masks, Mimes and Miracles:Studies in the Popular Theatre (NY: Cooper SquarePublisher, Inc, 1963) 71.

During the Middle Ages until 1200, theatrical activities were primarily performed within churches. These are usually referred to as liturgical dramas. Beginning in the late fourteenth century, religious drama became the prevailing dramatic style throughout most of Western Europe. According to Phyllis Hartnoll, the greatest comic character in the religious plays was Satan. Devils wore horrifying masks with beaks and horns, and costumes with wings or tails (see Fig. 2). After the scene of the Last Judgment, the Devil shoveled lost souls into a Hell-Mouth. Satan also provided interludes of acrobatic dancing and farcical miming between the scenes [9].

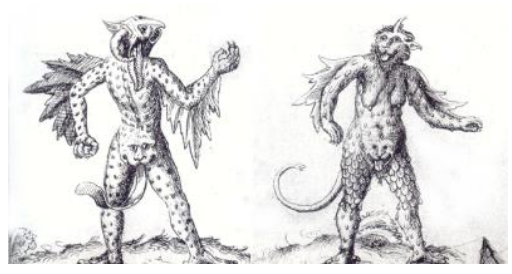

FIGURE 2.

TWO CHARACTERS OF MEDIEVAL DEVILS.

Phyllis Hartnoll, The Theatre: A Concise History (NY: Thames and Hudson, 1998) 47.

Secular drama was also still very popular during the Middle Ages. Some mimes followed the tradition of Roman mimic drama by ridiculing the clergy; however, some of them developed the so-called "Christian mime"-the mimic drama with a religious subject. As Nicoll points out, at that time, "In the Eastern Empire the mimes are still flourishing; in the west they are, on occasion, borrowing vestments from the cathedrals and the churches" [13]. Masks were also used in medieval secular drama. Among the most well-known characters were the jongleurs, a group which not only played the singers of the gests but who also imitated different people and even animals. Figure 2 shows a group of jongleurs in a medieval secular drama. Nicoll maintains that through the jongleurs' display of action, their costuming, and their utilization of masks, we can clearly infer a direct line of theatrical continuity of mimic drama [13].

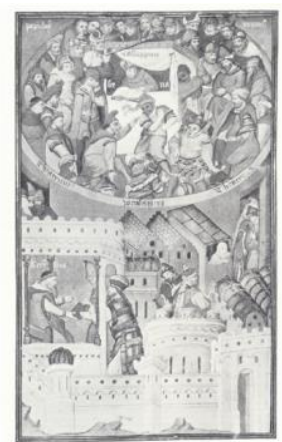

FIGURE 3. MEDIEVAL MIMES

Allardyce Nicoll, Masks, Mimes and Miracles: Studies in the Popular Theatre (NY: Cooper Square Publisher, Inc, 1963) 154

Historically, the Renaissance began when the Eastern Roman Empire collapsed and Constantinople fell to the Turks in 1453. Humanism, grounded in Christian and classical teaching, established the dominant Western thought which continues to the present day. As Brockett points out, the Renaissance was an era of expansion, through geographical survey, scientific investigation, philosophical inquiry, and artistic creativity [2]. One of the important influences in the theater was the application of perspective. Brockett writes that "the acceptance of perspective scenery is profoundly important, because it signaled a movement away from the architectural stage to the representational and pictorial stage" [3]. Another powerful trend was neoclassicism. One of the most influential dramatists of this style was Castelvetro, who lived in Italy around 1570 . He maintained that there should be a close correspondence between reality and art [1].

Following the tide of taste in realistic spectacle, the style and use of masks changed significantly. Masks covered less of the face, became more pliant, and softened into clown makeup. Russell Graves points out that these changes were accompanied by a corresponding softening in content and manner of performance, a process which was particularly evident in the commedia dell' arte in Italy during the sixteenth and seventeenth centuries [8]. The use of stock characters was one of the best-known features of commedia dell' arte. With the exception of performers acting as lovers, the other stock characters, masters and servants, had typical masks depicting their distinctive appearances and personalities [1].

Masks were necessary devices in commedia dell' arte until the eighteenth century, when the Italian comic dramatist Carlo 
Goldoni started to reform the genre. He campaigned for the abandonment of masks because he felt masks were very prejudicial to the action of the actor [2]. With the decline of commedia dell' arte, the use of masks lost its original appeal in the Western theater. However, masks have never completely disappeared. I believe that the multiple functions of masks ensure their survival. These functions fall into three domains:

1) Physiological: One of the main functions of the mask is to establish an association between actor and spectator. The actor appears to lose his/her real personality at the moment of donning a mask and transforming into another identity. Erika Fischer-Lichte argues that the face and the figure are not cultural phenomena; rather, they are determined by nature [6]. Each actor has physiological restrictions, such as gender, age, and skin color. Masks easily change these characteristics. Transformation is the original function of masks in the theater. They allow actors to effectively pretend to be someone (or even something) else on the stage.

2) Physical: Another function of the mask is to conceal the identity of a character from the other characters or from spectators. Hartnoll calls this an "aesthetic barrier" [9]. In ancient Greece, the mask was used as a cover to hide an actor's appearance and to enable a limited number of actors to play multiple roles. In this situation, the mask sets up a visual barrier between the actor's identity and the spectators' visual experience. However, a mask could also be worn to conceal an actor's identity in the play. Through its physicality, the mask generates suspense, confusion, or horror. Behind a mask, there could be a disfigured lover, a chivalrous hero, or a psychotic killer. In these situations, instead of being used to create a character, the mask is used as a device of physical concealment.

3) Psychological: The relationship between acting and identity is complicated. Thomas Morawetz believes that "role itself is typically not the creation of the actor but of the playwright; the actor is the medium through which the playwright speaks to the audience" [12]. How does a mask help the actor become the medium between playwright and audience? Rupert D. V. Glasgow claims that a caricatural mask is a product of the twin processes of "metonymic simplification and hyperbole" [7]. Exaggeration can create either awe or comicality. Diana Devlin believes that the mask can increase the actor's dignity; she points out that in the late period of Greek theater, masks were often bigger than human faces and, together with heightened shoes, made the actor literally larger than life [4]. On the other hand, the creation of masks could be regarded as a process of semiosis. From a semiotic point of view, masks simplify complex personalities and change them into stock characters to create collectively accepted signifiers. For this reason, Fischer-Lichet maintains that "the mask as a theatrical sign does not denote natural facts, but rather cultural phenomena" [6]. This collective psychological function has resulted in the success of the mask as a theatrical device throughout the long history of theater.

\section{AN EXPLORATION OF PAINTED FACES IN PEKING OPERA}

The origin of theatrical activities in China can be traced back to early rituals of shamanism which, combined with dance, song, gesture, posture, and costume, were almost parallel to those in Greece (Dolby 8). Historical literature shows that formal theater emerged during the Han Dynasty (206 B.C.-A.D. 220) and developed into various styles in different areas [17]. The performance style of today's opera was established in 1790 when the emperor assembled four regional theatrical groups at the capital of Peking, to celebrate his birthday. These four groups modified elements of their performance styles and changed the accent used in the songs and dialogue to adapt to local customs, such that they gradually entered the mainstream of Chinese theatrical arts [17].

One of the most typical features of the Peking opera is its use of vivid makeup, especially in its variety of painted faces. The idea of the painted face was derived from the mask. In the Tang Dynasty, Emperor Xuanzong (A.D. 712-756) patronized actors and sponsored performances in the palace. Records show that masks with painted decorations were used in some of these performances. Shao-Zhou Wang points out that in traditional performances the masks were held in the mouth. The masked actor did not sing or talk and, if necessary, was dubbed by another actor. As the performing style gradually changed and vocal parts became increasingly more important, the use of painted faces eventually replaced masks [16]. Yuan Ju analyzed a fresco which is believed to have been created around A.D. 1324 during the Yuan Dynasty (See Fig. 4) [10, 14]. He pointed out that the second figure from the left standing in the front row is apparently a clown character with a painted face. This is the earliest image of the painted face in the historical record [16].

The development of painted faces was affected by performing style. Yong-Yi Zeng concludes that there are three characteristics of Chinese opera: first, the plots are based on well-known historical or literary stories; second, dialogue and song are expressed in the form of poetry; and third, the performance is combined with music, dance, and acrobatics [17].

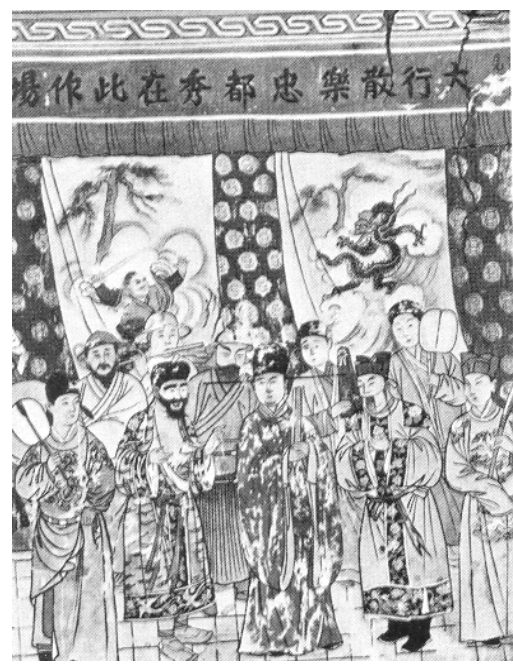

FIGURE 4

SCENE FROM A YUAN DRAMA.

A. C. Scott, "The performance of classical theater." Chinese Theater: From Its Origins to the Present Day. Ed. Colin Mackerras (Honolulu, HI: University of Hawaii Press, 1983) 130. 


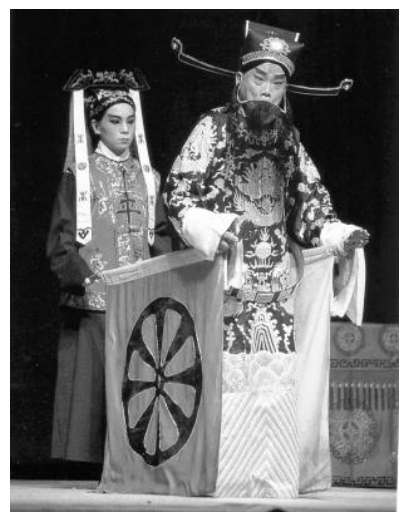

FIGURE 5.

A SYMBOLIC VEHICLE IN CHINESE PEKING OPERA

Zeng, Yong-Yi, Chinese Traditional Opera (Taipei: Han Guang Culture Press, 1998) 110.

Though the subjects of Chinese opera are mostly derived from history and literature, the visual expression is always symbolic. Scenery and property are simplified. For example, fringed sticks are always used to represent horses; two flags decorated with wheels are the common devices to symbolize a vehicle (shown in Fig. 5) [17]. The concept of painted faces is also based on symbolism. In order to explore the significance of this art, an exploration of the arrangement of characters is necessary.

Chinese opera can be divided into two basic categories: civil plays and military plays. The former are lyrical and concerned with social issues. This style usually emphasizes dialogue and singing. The military plays are boisterous, concerned with military issues, and usually include various martial arts and acrobatics. Characters are classified under four titles. Dan is the female role; all female roles call for strong makeup except for the role of old lady. Before the end of the nineteenth century, female actresses were prohibited; therefore all the roles of dan were played by male actors. Sheng is the male role; most male roles call for straight makeup only, and beards are used to distinguish age. Jing is the male role with a strong disposition; most of the painted faces we see fall into this category of characters. Chou is the clown, played by a male, and also calls for a painted face. Knowing how to paint a face became a skill required of the actors of jing and chou (see Fig. 6) [15].

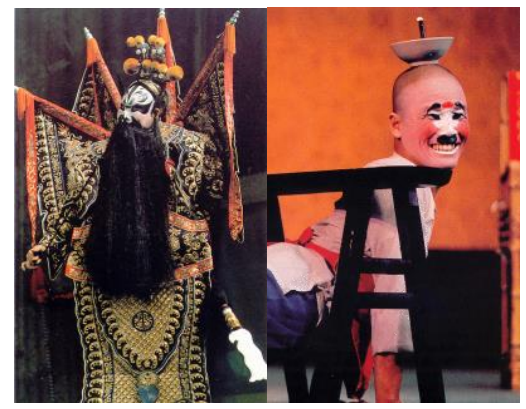

FIGURE 6.

JING (LEFT) AND CHOU: TWO CATEGORIES OF PAINTED FACE ROLES.

Siu, ang-Ngai, Chinese Opera: Images and Stories, (Seattle, WA: Uni versity of Washington University Press, 1997) 85,145
Painted makeup is applied using three techniques: spreading, drawing, and dyeing. The material used in the technique of spreading is white powder. All the roles of chou and some sinister roles of jing require spreading. Chou's makeup, however, covers only the nose and eyebrows. Dyeing refers to the use of oil pigment to dye the whole face a single color. Today, it is rarely used. Drawing is the most popular method used for painting faces. The facial expression of the character is exaggerated through color and line.

The functions of painted faces in Chinese opera can be summarized as follows: first, painted faces demonstrate status. Each painted-face character has an exclusive facial pattern; the audience can easily recognize his status. Second, painted faces are used to express personality. In Chinese opera, red represents loyalty and justice; black means frankness and bravery; white is used in sinister and false roles; yellow is cunning; blue and green signify ferocity; gold and silver symbolize dignity and are usually used for the roles of deities. The third function of painted faces is to simplify the production. Facial patterns can indicate various animals; in some mythic plays, painted faces enable actors to be disguised as non-human characters, replacing the need for puppets or extra devices. Finally, and most importantly, the painted faces in the Peking opera represent a unique cultural achievement in theatrical art.

\section{A COMPARISON OF PAINTED FACES AND MASKS IN THEATRICAL ART}

Although the invention of painted faces in Peking opera is attributed to the earlier use of masks, masks and painted faces are ontologically different. The mask is a physical object; its expression is fixed and frozen. A mask can conceal the actor's original face and transform him/her into a different figure. Like masks, painted faces can represent actors' identities; however, painted makeup intimately adheres to the actors' real faces. The colorful patterns melt into the actors' human expressions, combine reality with artificiality, and create fantastic images.

Masks and painted faces are similar in shaping specific characters. In Roman comedy and Italian commedia dell' arte, masks successfully created stock characters. In Peking opera, each character possesses an historical or literary identity. However, the use of painted faces also helps the audience to recognize particular aspects of the roles. Glasgow claims that "[h]uman behavior in general naturally has a tendency to slip into standardized routine and regularity, to congeal into repetitive fixity, our traits of character being modes of comportment seen as recurrent" [7]. Thus, he argues, the aesthetic experience generated by masks in the theater is derived from the effects of repetition and predictability [7]. Glasgow's theory not only explains why masks were popularly used in commedia dell' arte, but it may also explain why the audience was satisfied with the fixed pattern of a typical character who repeatedly appeared on the stage.

Two factors may have resulted in differences in development of masks and of painted faces. One is performing space; the other is performing style. The seating capacity of the early Greek theater was enormous. The theater of Dionysus could hold at least fourteen thousand spectators. Brockett 
suggests that the scale of the structure can help us understand some conventions of Greek theater [3]. Masks helped to enlarge figures and magnify facial expressions in such circumstances. Later, when the scale of theaters was smaller, masks interfered with exquisite facial expressions. This would seem to explain why masks were softened and reduced to half face, ultimately ceasing to be necessary in western theaters. By contrast, the scale of Chinese theater is smaller. The traditional village theater was a temporary wooden or bamboo shack. Some permanent theaters in the larger cities were called "tea houses" [11]. In both theater spaces, the distance between actors and spectators was very small (see Fig. 7).

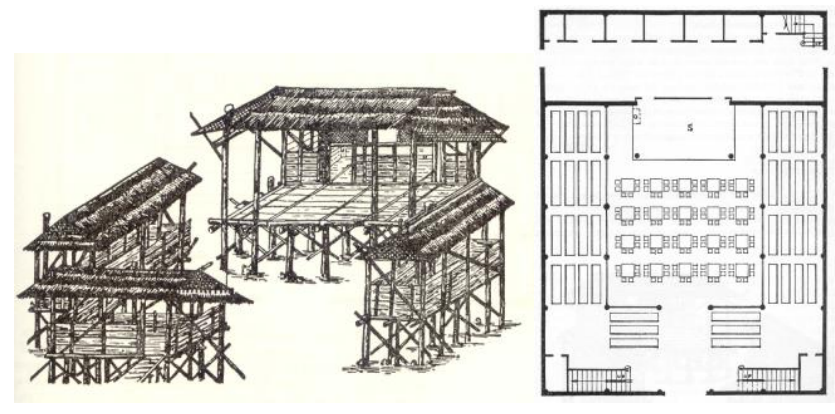

FIGURE 7.

TRADITIONAL CHINESE THEATERS: VILLAGE THEATER (LEFT) AND TEA HOUSE.

Macgown, Kenneth and Melnitz, William. The Living Stage: A History of the World Theater (Englewood Cliffs, NJ: Prentice-Hall, 1955) 305, 306.

It would be an overstatement to conclude that the scale of performing space resulted in the development of painted faces, but it is reasonable to infer that a small staging space would allow painted faces to suffice for audiences to identify characters. Elaborate makeup and mutable expressions were visible from a short distance.

Performing style is another important factor in the differing development of masks and painted faces. After commedia dell' arte faded away during the eighteenth century, romanticism and realism, in turn, influenced theatrical art during the nineteenth century and early twentieth century. Melodrama is the representative dramatic style of romanticism. According to Brockett, the performing styles of both melodrama and realism were basically realistic [3]. Masks and strong makeup are obviously not suitable for realistic staging in the western theater. At the same time in China, under the Ching Dynasty, the whole of society was closed and conservative. Symbolic staging accompanied by the use of painted faces became a constant of Peking opera.

\section{CONCLUSION}

Masks and painted faces appeal to visual experience. Although Aristotle considered spectacle less important than the other six elements of dramatic action he described (plot, character, thought, diction, and music), visual effect is one of the most direct ways to draw attention and to evoke emotion. Viola Spolin states that "[e]very technique learned by the actor, every curtain and flat on the stage, every careful analysis by the director, every coordinated scene, is for the enjoyment of the audience" [3]. In this perspective, the development of both masks and painted faces is significant. Masks and painted faces have enriched theatrical art and contributed to the popularity of theatrical activities over time. Indeed, just as the mask is used as a metaphor in western society to express a hypocritical person or a disguised identity, so too the painted face is used in Chinese society. Each of these devices has become symbolic in the culture each represents.

\section{REFERENCES}

[1] Brockett, Oscar. G. The Theatre: An Introduction. NY: Holt, Rinehart and Winston, 1974.

[2] Brockett, Oscar. G. History of the Theatre. Needham Heights, MA: A Simon \& Schuster Company, 1995.

[3] Brockett, Oscar. G. The Essential Theatre. Belmont, CA: Thomson Learning, 2000.

[4] Devlin, Diana. Mask and Scene: An Introduction to a World View of Theatre. Metuchen NJ: The Scarecrow Press, 1989.

[5] Dolby, William. "Early Chinese Plays and Theater." Chinese Theater: From Its Origins to the Present Day. Ed. Colin Mackerras. Honolulu, HI: University of Hawaii Press, 1983. 7-31.

[6] Fischer-Lichte, Erika. The Semiotics of Theatre. Trans. J. Gaines and D. L. Jones. Bloomington, IN: Indiana University Press, 1992.

[7] Glasgow, Rupert. D. V. Madness, Masks, and Laughter: An Essay on Comedy. Teaneck, NJ: Fairleigh Dickinson University Press, 1995.

[8] Graves, Russell. "The Psychological Effects of Masks." The theatre crafts: Book of make-up, masks, and wigs. Ed. C. Ray Smith. Emmaus, PA: Rodale Press, 1947. 168-176.

[9] Hartnoll, Phyllis. The Theatre: A Concise History. NY: Thames and Hudson, 1998.

[10] Ju, Yuan. Collection of Facial Symbolism in Chinese Opera. Taipei: Shu Xin Publisher, 1988.

[11] Macgown, Kenneth and Melnitz, William. The Living Stage: A History of the World Theater. Englewood Cliffs, NJ: Prentice-Hall, 1955.

[12] Morawetz, Thomas. Making Faces, Playing God: Identity and the Art of Transformational Makeup. Austin, TX: University of Texas Press, 2001.

[13] Nicoll, Allardyce. Masks, Mimes and Miracles: Studies in the Popular Theatre. NY: Cooper Square Publisher, Inc, 1963.

[14] Scott, A. C. "The performance of classical theater." Chinese Theater: From Its Origins to the Present Day. Ed. Colin Mackerras. Honolulu, HI: University of Hawaii Press, 1983. 118-144.

[15] Siu, Wang-Ngai. Chinese Opera: Images and Stories. Seattle, WA: University of Washington University Press, 1997.

[16] Wang, Shao-Zhou. "Interpretation of Painted Faces in Chinese Opera." Chinese Opera. Ed. Han Guang Culture Company. Taipei: Han Guang Culture Press, 1981. 145-147.

[17] Zeng, Yong-Yi. Chinese Traditional Opera. Taipei: Han Guang Culture Press, 